\title{
Detection and Characterization of Bovine Rumen Microorganisms Resistant to Sodium Fluoroacetate
}

\author{
Maria Fernanda Aranega Pimentel', Daphine Ariadne Jesus Paula', Franklin Riet-Correa², \\ Valéria Dutra' ${ }^{1}$ Luciano Nakazato' ${ }^{1}$
}

\begin{abstract}
Background: Poisoning of animals due to toxic plants is found in Brazil and other countries. One of the known toxic plants in Brazil, with the active ingredient sodium fluoroacetate (SF), is Palicourea marcgravii. Dehalogenases that inactivate the fluor-carbon bonds are enzymes found in microorganisms and may prevent intoxication. This study evaluated the occurrence of rumen microorganisms naturally resistant to SF.

Materials, Methods \& Results: Two samples of rumen fluid of cattle from the Experimental Farm of Federal University of Mato Grosso fed with Brachiaria sp. were obtained via fistula in flasks. An aliquot of $2 \mathrm{~mL}$ was placed in a microtube and centrifuged at $9000 \mathrm{~g}$ for $1 \mathrm{~min}$. Then, the sample was inoculated into 2 tubes, one containing $100 \mu \mathrm{L}$ of clarified rumen fluid in $2 \mathrm{~mL}$ of modified liquid culture medium $(0.1 \%$ ammonium sulfate, $0.1 \%$ potassium phosphate monobasic, $0.05 \%$ sodium phosphate dibasic, $0.01 \%$ magnesium sulfate, $0.01 \%$ yeast extract, $\mathrm{pH} 7.0$ ) and $0.4 \%$ of SF and the other sample containing $2 \mathrm{~mL}$ of liquid culture medium and $100 \mu \mathrm{L}$ of clarified rumen fluid. The 2 samples were incubated at $40^{\circ} \mathrm{C}$ for $24 \mathrm{~h}$. Dilutions were performed under the same conditions every $24 \mathrm{~h}$ until the attainment of microorganisms resistant to $\mathrm{SF}$, and the finaldilution containing $50 \mu \mathrm{L}$ of each sample was plated in the middle containing SF $(0.4 \%)$ and incubated at $40^{\circ} \mathrm{C}$ for $24 \mathrm{~h}$ for the isolation of bacteria. The bacterial colonies resistant to SF were identified by morphological methods, stained, and subjected to DNA extraction sequencing using the universal primers $27 \mathrm{f}$ and $1492 \mathrm{r}$ (16S rDNA) for the identification of the bacterial genus using Blast DNA identity analysis. These bacteria were cultured with and without SF $(0.4 \%)$, and the presence of fluoride ions was detected by an ion-selective electrode (fluoride) during incubation for 0,30 , 60, 90, and $120 \mathrm{~min}$. Two resistant microorganisms were isolated, one was a Gram-positive coccus and the other was a Gram-positive rod. DNA sequencing identified these organisms as Enterococcus faecalis (98\% identity Genbank 1358689) and Bacillus sp. (89\% identity Genbank 1358671). Fluoride ions were detected more at 60-min incubation time in both $E$. faecalis $(0.0560 \mathrm{ppm})$ and Bacillus sp. $(0.0488 \mathrm{ppm})$. Bioassay protection tests were performed in mice ofthe following four groups: negative control (NC) with saline administration, positive control (PC) with administration of plant containing SF, Bacillus group (BG) with administration of plant containing SF plus Bacillus sp., and coccus group (CG) with administration of SF and E.faecalis. Clinical signs were recorded, and statistical analyses were performed to confirm the differences in the groups. Bioassay protection tests showed clinical signs of intoxication in the PC group (83.3\%), BG group (100\%), and CG group (16.6\%) but not in the NC group $(0 \%)$, with a statistical difference between GC and PC groups $(P<0.05)$. Discussion: Several environmental bacteria possessing dehalogenase activity have been described, such as Pseudomonas sp., Moraxella sp., and Burkholderia sp. and Pigmentiphaga kullae and Ancylobacter dichloromethanicus isolated from the rumen. No previous study has yet reported an association between dehalogenase activity and E. faecalis, and the protection assay has been observed only in the E. faecalis group. Similar results were observed in experimental intoxication in goats that had previously consumed SF, with the microorganisms identified being Pigmentiphaga kullae and Ancylobacter dichloromethanicus. E. faecalis, isolated from the bovine rumen, exhibited a dehalogenase activity, which could help control animal poisoning by plants containing SF.
\end{abstract}

Keywords: sodium fluoroacetate, Palicourea marcgravii, dehalogenase, rumen.

DOI: $10.22456 / 1679-9216.89907$

${ }^{1}$ Laboratory of Microbiology and Molecular Biology, Veterinary Hospital, Federal University of the State of Mato Grosso (UFMT), Cuiabá, MT, Brazil. ${ }^{2}$ Center for Health and Rural Technology (CSTR), Federal University of Campina Grande (UFCG), Campus of Patos, PB, Brazil. CORRESPONDENCE: M.F.A. Pimentel [aranegapimentelvet@ hotmail.com - Tel.: +55 (65) 3615-8625]. Laboratory of Microbiology and Molecular Biology, Veterinary Hospital, UFMT. Av. Fernando Correa da Costa n. 2367. CEP 78060-900 Cuiabá, MT, Brazil. 


\section{INTRODUCTION}

Poisonous plants cause much damage in Brazilian cattle industry, among the poisonous plants that cause a clinical pathological study of sudden death is Palicourea marcgravii $[11,14,15]$. The active ingredient present in this plant is the sodium fluoroacetate (SF) that is lethal, even when consumed in small quantities, because the substance inhibits the Krebs cycle, and its cumulative effect. Plants with this principle are found in Brazil and other countries like Australia and Africa.

Some bacteria are capable of producing dehalogenases, which are enzymes whose action is to detoxify the SF, this has been an alternative for control and prevention of disease. In Australia a study where a ruminal bacterium Butyrivibrio fibrisolvens has been genetically modified with a gene, encoding the dehalogenase isolated from environmental bacterium Moraxella sp. Strain B. And the results were satisfactory and workable in vitro and in vivo $[4,5]$.

The enzyme capable of cleaving the strong carbon-fluorine bond $(\mathrm{CF})$ present in the SF is a dehalogenase, which is specific for this substrate, but she is also able to cleave other bonds less effectively as carbon-chlorine and carbon-bromine [9]. There are other dehalogenases belonging to the same group of fluoroacetate dehalogenase, the Haloacetato Halidohydrolases, but are not able to cleave this strong connection [3].

Today, Brazil is considered as a major producer of cattle raised on pasture, and maintain this condition is very important to the economy. Therefore, this study aims to find in the rumen bacteria that are resistant to the SF for possible use in detoxification methods.

\section{MATERIALS AND METHODS}

\section{Rumen fluid}

Two adults bovines samples of rumen fluid were used from Experimental Farm of Universidade Federal de Mato Grosso, grazing Brachiaria sp. The rumen fluid was obtained via fistula in flasks and kept refrigerated until processing. An aliquot of $2 \mathrm{~mL}$ of each animal was placed in microtube and centrifuged at $9000 \mathrm{~g}$ for $1 \mathrm{~min}$ and supernatant were mixed in one tube (clarified rumen fluid).

\section{Microorganisms}

To obtain possible resistant microorganisms, 100 $\mu \mathrm{L}$ of clarified rumen fluid sample were inoculated in two different tubes: $2 \mathrm{~mL}$ of liquid culture medium $(0.1 \%$ am- monium sulfate, $0.1 \%$ potassium phosphate monobasic, $0.05 \%$ sodium phosphate dibasic, $0.01 \%$ magnesium sulfate, $0.01 \%$ yeast extract, $\mathrm{pH} 7.0$ ) [9] containing $0.4 \%$ of SF (Sodium fluoroacetate solution) ${ }^{1}$, and the other sample with $2 \mathrm{~mL}$ of liquid culture medium. Samples were incubated at $40^{\circ} \mathrm{C}$ with moderate shaking for $24 \mathrm{~h}$.

Dilutions from tube with SF $\left(10^{-1}\right.$ to $\left.10^{-5}\right)$ were performed under the same conditions every $24 \mathrm{~h}$. The last dilution were plated $50 \mu \mathrm{L}$ of each sample in the middle [9] containing SF $(0.4 \%)$, and incubated at $40^{\circ} \mathrm{C}$ for $24 \mathrm{~h}$ for the isolation of bacteria. The bacterial colonies isolates were identified by morphological and staining [12].

\section{DNA extraction}

Samples of bacteria were isolated and subjected to DNA extraction method by phenol/chloroform [13]. The polymerase chain reaction (PCR) was performed with universal primers $27 \mathrm{f}$ ( $5^{\prime}$-AGA GTT TGA TCC TGG CTC AG-3 ') and 1492r (5'-GGT TAC CTT GTT ACG ACT T-3') [8]. The amplicon were sequenced with ABI-PRISM 3100 Genetic Analyzer and were analyzed by BLAST (http://www.ncbi.nlm.nih.gov/Genbank/ índex.html) for identification of microorganisms.

The isolated bacteria and transforming pETLysS-FA1 were grown in liquid medium [9] for $24 \mathrm{~h}$ at $40^{\circ} \mathrm{C}$ and $100 \mu \mathrm{L}$ was inoculated into $20 \mathrm{~mL}$ of the same medium plus the same amount of buffer TISAB II (sodium chloride, glacial acetic acid, EDTA, pH $5.3 \pm 0.03$ ). Rumen bacteria were cultured with and without SF $0.4 \%$, and transforming pET-LysS-FA1 was grown with and without IPTG. The presence of fluoride ions were detected by $\mathrm{pH}$ meter (HI $3222 \mathrm{pH}$ / ORP / ISE meter) ${ }^{2}$ and ion selective electrode (ISE) [HI 4110 combination Fluoride $]^{2}$.

\section{Protection activity of $S F$}

To verify capability of protection activity of these SF resistant bacteria a protection assay were performed in mice. Twenty-four adult mices with an average of $30 \mathrm{~g}$ were divided into 4 groups with 6 animals each: negative control (NC) with saline administration, positive control (PC) with administration of SF, Bacillus group (BG) with administration of rod-shape bacteria and coccus group (CG). Rumen isolated coccus and rod-shape bacteria were inoculated in $3 \mathrm{~mL}$ of Luria Bertania broth grown "overnight", and $60 \mu \mathrm{L}$ were administered orally for 7 days for group $\mathrm{CG}$ and $\mathrm{BG}$, respectively. For all groups, except $\mathrm{NC}$, were administered a daily dose of $0.266 \mathrm{mg}$ FS / $\mathrm{kg}$ for 7 days. 


\section{Statistical analysis}

Statistical analysis ( $t$ test) was performed to compare difference in fluorite concentration in media with and without SF. Comparison of clinical sings variation in groups receiving or not resistant bacteria were tested by Chi-square test.

\section{RESULTS}

The samples were collected from animals fed naturally, not to promote or inhibit the growth of bacteria themselves of rumen. Using a medium containing nutrients and low in SF as the sole carbon source were isolated from 2 rumen bacteria that survived and grew in this medium. The medium used for isolation of ruminal bacteria was the same used by Kurihara et al. [9], with only two modifications, we used sodium phosphate dibasic instead of potassium phosphate dibasic for both liquid and solid as for the agar-agar (2\%) for solid medium.

Isolated microorganisms survived and grew in the presence of SF. When subjected to Gram stain, the bacteria showed a characteristic morphology of a rod-shape and the other of a coccus, and both were Gram stain positive. The strains isolated from rumen fluid that grew in the presence of SF showed colonies of mucoid aspect and creamy.

Table 1. Variation of the fluoride ion in cultures of rumen bacteria selected under the action of sodium fluoroacetate.

\begin{tabular}{ccccc}
\hline Time & \multicolumn{2}{c}{ Control $^{*}$} & \multicolumn{2}{c}{ Sodium monofluoracetate $^{*}$} \\
\hline$(\min )$ & Coccus & Bacillus & Coccus & Bacillus \\
0 & 0.00200 & 0.00189 & 0.0293 & 0.0272 \\
30 & 0.00100 & 0.00100 & 0.0264 & 0.0244 \\
60 & 0.00106 & 0.00100 & 0.0560 & 0.0488 \\
90 & 0.00110 & 0.00100 & 0.0471 & 0.0447 \\
120 & 0.00100 & 0.00100 & 0.0482 & 0.0457 \\
\hline
\end{tabular}

*ppm= parts per million.

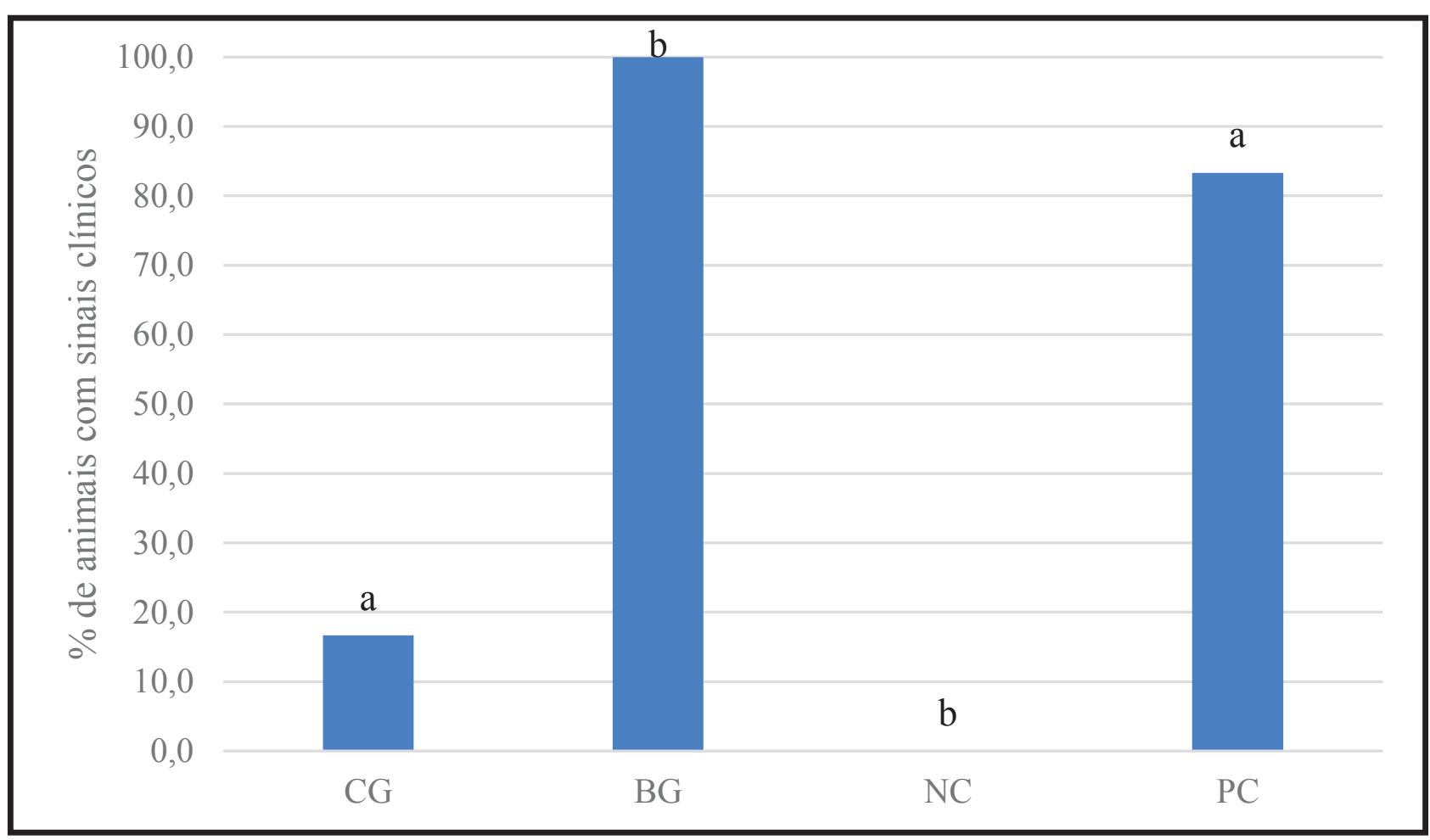

Figure 1. Clinical evaluation in mouse protection bioassay against plant extract with SF. BG= group with previous Bacillus sp. administration; CG= group with previous Enterococcus faecalis administration; $\mathrm{NC}=$ negative control with saline administration; $\mathrm{PC}=\mathrm{Positive}$ control (PC) with administration of SF plant. ${ }^{\mathrm{a}, \mathrm{b}}=P<0.05$. 
Of the 2 isolated bacteria were performed PCR, the bands amplified $1497 \mathrm{pb}$, where we use the same method used by Kurihara et al. [9] and proves that they are bacteria. After sequencing, coccus bacteria was identified as the genus Enterococcus. These bacteria are gram positive cocci that may be present alone, in pairs or short chains [12]. Organisms are catalase and oxidase negative and furniture that grow in medium with $6.5 \% \mathrm{NaCl}$ and McConkey [12]. This organism has been isolated from the rumen of different species of both domestic and wild ruminants [6-8,10,17].

Rod-shape bacteria isolated belong to the genus Bacillus, and constitute a broad group, which usually have positive or Gram variable and are mobile (except B. anthracis and B. mycoides) [12]. Microorganisms are aerobic or facultative anaerobes and catalase positive that do not grow on McConkey agar. This organism has been isolated from the rumen [17].

The measurement performed with the ISE likely to demonstrate that the amount of fluoride ions increased considerably in the presence of sodium fluoroacetate in the cultures of two bacteria (Table 1). Whereas without the fluoroacetate levels of fluoride ion remained basal. When subjected to the toxic behavior of the 2 bacteria selected in this study was different. After inoculation of the sample in half, the culture of Enterococcus faecalis showed the highest level of fluoride ion, $0.0560 \mathrm{ppm}$, compared with that of Bacillus sp. 0.0488 ppm.

It has been observed the presence of dehalogenases in environmental bacteria such as Pseudomonas sp., Moraxella sp. and Burkholderia sp. [3]. The occurrence of microorganisms capable of degrading fluoroacetates has been observed in soil microorganisms in Australia, even without the presence of the compound as observed in this study, indicating that this mechanism of occurrence of these microorganisms can be universal or rapidly induced [16]. In Brazil, 2 microorganisms with the capacity to degrade sodium Fluoroacetate were isolated from the rumen of goats, Pigmentiphaga kullae and Ancylobacter dichloromethanicus [2].

In protection bioassay, mice with clinical signal observed are despicted (Figure1). The clinical signs observed were intense cyanosis, bradycardia, convulsions and death. All animals in BG shows clinical signs and died and in CG only one animal died. PC group all except one animal show clinical signals. In NC all animal were heathly during experiment.

\section{DISCUSSION}

The microorganisms isolated in this work survived and grew in the presence of SF, which indicates that these strains showed resistance to SF and can use this substance for their propagation, where only SF, with its strong CF bonds, was present as the only carbon source.

The present results were satisfactory when compared with measurements performed by Gregg et al. [5], even though the method used by him was different, where we used the cell-free extract to perform the measurement with the ISE, the ion concentrations fluoride detected by it was between 0.2 to $0.6 \mathrm{mM}$.

It has been observed the presence of dehalogenases in environmental bacteria such as Pseudomonas sp., Moraxella sp. and Burkholderia sp. [3]. The occurrence of microorganisms capable of degrading fluoroacetates has been observed in soil microorganisms in Australia, even without the presence of the compound as observed in this study, indicating that this mechanism of occurrence of these microorganisms can be universal or rapidly induced [16]. In Brazil, two microorganisms with the capacity to degrade sodium Fluoroacetate were isolated from the rumen of goats, Pigmentiphaga kullae and Ancylobacter dichloromethanicus [2].

Attempts to identify a rumen microorganism that has the fluoroacetate dehalogenase gene is a challenge, and so far, it has not been reported. However, this study aimed to find a rumen microorganism capable of degrading the SF, as did Allison et al. [1], who isolated a microorganism, ruminal Synergistes jonesii in Australia, a bacterium able to degrade the toxic substance present in Leucaena leucocephala, the mimosine [3-hydroxy-4 (1H)-pyridone (3,4-DHP)].

Other alternatives have been used to solve the problem of poisoning, as modification of rumen bacteria Butyrivibrio fibrisolvens held by Gregg et al. [4], and trial of this bacteria in sheep by the same researcher [5] in Australia. But finding one's own rumen microorganism that degrades the sodium fluoroacetate would solve many problems.

\section{CONCLUSIONS}

The microorganisms isolated in this study not only resisted sodium fluoroacetate, but one of them, Enterococcus faecalis avoided the appearance of clinical signs in animals poisoned by SF, and may be used in future experiments to obtain solutions to the problem of intoxication. 


\section{MANUFACTURERS}

${ }^{1}$ Sigma-Aldrich. St. Louis, MO, USA.

${ }^{2}$ Hanna Instruments. São Paulo, SP, Brazil.

Ethical approval. The Animal Research Ethics Committee of the Federal University of State of the Mato Grosso - UFMT
- Brazil n² 23108.052786 / 12-0 approved the experimental procedures.

Declaration of interest. The authors report no conflicts of interest. The authors alone are responsible for the content and writing of paper.

\section{REFERENCES}

1 Allison M.J., Mayberry W.R., McSweeney C.S. \& Stahl D.A. 1992. Synergistesjonesii, gen. nov., sp. Nov.: A rumen bacterium that degrades toxic pyridine diols. Systematic and Applied Microbiology. 15(4): 522-529.

2 Camboim E.K.A., Almeida A.P., Tadra-Sfeir M.Z., Junior F.G., Andrade P.P., McSweeney C.S., Melo M.A. \& Riet-Correa F. 2012. Isolation and identification of Sodium Fluoroacetate degrading bacteria from caprine rumen in Brazil. The Scientific World Journal. 2012: 178254.

3 Fetzner S. \& Lingens F. 1994. Bacterial Dehalogenases: Biochemistry, Genetics, biotechnological and Applications. Microbiological Reviews. 58(4): 641-685.

4 Gregg K., Cooper C.L., Schafer D.J., Sharpe H., Beard C.E., Allen G. \& Xu J. 1994. Detoxification of the plant toxin fluoroacetate by a genetically modified rumen bacterium. Nature. 12: 1361-1365.

5 Gregg K., Hamdorf B., Henderson K., Kopecny J. \& Wong C. 1998. Genetically modified ruminal bacteria protect sheep from fluoroacetate poisoning. Applied and Environmental Microbiology. 64(9): 3496-3498.

6 Hudson J.A., Cai Y., Corner R.J., Morvan B. \& Jobline K.N. 2000. Identification and enumeration of oleic acid and linoleic acid hydrating bacteria in the rumen of sheep and cows. Journal of Applied Microbiology. 88: 286-292.

7 Hudson J.A., Mackenzie C.A. \& Jobline K.N. 1996. Factors affecting the formation of 10-hydroxystearic acid from oleic acid by a ruminal strain of Enterococcus faecalis. Applied Microbiology and Biotechnology. 45: 404-407.

8 Hudson J.A., Morvan B. \& Jobline K.N. 1998. Hydration of linoleic acid by bacteria isolated from ruminants. FEMS Microbiology Letters. 169: 277-282.

9 Kurihara T., Yamauchi T., Ichiyama S., Takahata H. \& Esaki N. 2003. Purification, characterization, and gene cloning of a novel fluoroacetate dehalogenase from Burkholderiasp FA1. Journal of Molecular Catalysis. 23: 347-355.

10 Lauková A. \& Koniarová I. 1995. Survey of urease activity in ruminal bacteria isolated from domestic and wild ruminants. Microbios. 84: 7-11.

11 Medeiros R.M.T., Geraldo Neto S.A., Barbosa R.C., Lima E.F. \& Riet-Correa F. 2002. Sudden death from bovine Mascagniarigida in Northeastern Brazil. Veterinary and Human Toxicology. 44: 286-288.

12 Quinn P.J., Carter M.E., Markey B. \& Carter G.R. 1994. Clinical Veterinary Microbiology. Liège: Mosby Year Book Europe Ltd., pp.127-183.

13 Sambrook J. \& Russell D.W. 2001. Molecular Cloning - A laboratory Manual. 3rd edn. New York: Cold Spring Harbor Laboratory Press, 2100p.

14 Tokarnia C.H., Döbereiner J. \& Peixoto P.V. 2000. Poisonous plants of Brazil. Rio de Janeiro: Helianthus, 311p.

15 Tokarnia C.H., Döbereiner J. \& Peixoto P.V. 2002. Poisonous plants Affecting livestock in Brazil. Toxicon. 40: 1635-1660.

16 Wong D.H., Kirkpatrick W.E., King D.R. \& Kinnear J.E. 1992. Defluorination of sodium monofluoroacetate (1080) by microorganisms isolated from Western Australian soils. Soil Biology and Biochemistry. 24(9): 833-838.

17 Yanke L.J., Bae H.D., Selinger L.B. \& Cheng K.J. 1998. Phytase activity of anaerobic ruminal bacteria. Microbiology Society. 144: 1565-1573. 